\title{
B-Learning Tools in Engineering Education
}

\author{
http://dx.doi.org/10.3991/ijep.v3i2.2451 \\ R. Maceiras ${ }^{1}$, A. Cancela ${ }^{2}$, A. Sánchez ${ }^{2}$ and S. Urréjola ${ }^{1}$ \\ 1 University of Vigo (CUD), Marín, Spain \\ ${ }^{2}$ University of Vigo (ETSEI), Vigo, Spain
}

\begin{abstract}
The New Higher Education System implies the adoption of different education systems than the traditional ones. Therefore, many college teachers today want to use some new mechanisms to teach the matter and to find better ways of engaging students in the learning process. The objective of this work is to evaluate different learning methods from the student's point of view and share the authors' experience towards a different mode of teaching. Three different learning techniques have been used on University of Vigo's fifth-year engineering students and the students have answered a questionnaire in order to check the effectiveness of the different methods from the students' point of view. The results of the experience show that the use of learning methods (cooperative learning and multimedia resources) fosters student motivation and improves their retention, assimilation, understanding, and proper application of course content.
\end{abstract}

Index Terms - cooperative learning, chemical engineering, active learning, higher education, student involvement.

\section{INTRODUCTION}

The teaching and learning processes have been considered for long time as individual processes with the aim to an "inert knowledge", properly defined by Whitehead [1], who said that the main problem of all educational systems was "the problem of keeping knowledge alive, of preventing it from becoming inert". This system of education is based on the belief that assessment of learning could be "measured" through objective evidence, often standardized, with multiple-choice questions. Such assessment systems have encountered lots of critical comments [2-4]. However, in recent years the education at Universities is changing to adapt current degrees to new European regulation and guidelines, where the aim is to introduce diverse teaching techniques to improve the learning process [5].

This new vision of the whole educational system can be defined as learner-centred and not teacher-centred because it requires all teachers, to rethink their own practice, to construct new classroom roles and expectations about student outcomes, and to teach in ways they have never taught before - and probably never experienced as students. Learner-Centred Education is defined by McCombs and Whisler [6] as: "The perspective that couples a focus on individual learners (their heredity, experiences, perspectives, backgrounds, talents, interests, capacities, and needs) with a focus on learning (the best available knowledge about learning and how it occurs and about teaching practices that are most effective in promoting the highest levels of motivation, learning, and achievement for all learners)". Following this line, the idea of the Bologna process is looking for an improvement on the quality of the students, and creating a more interactive and motivational environment for students and teachers [5]. For that reason, The New Higher Education System (NHES) implies the adoption of different education systems than the traditional ones. Subjects are defined in terms of competencies. The students need to achieve some specific competencies and some generic competencies. The specific competencies are based on the field of study; whereas the generic ones are related with some capabilities of the students with the environment, such as relationships, oral and writing communication, make decisions, team work, job ethical behaviour, leadership, motivation, and so on. In this way, the teacher may use some new mechanisms to teach the matter under study.

Nevertheless, the adaptation of subjects to the European Higher Education Area (EHEA) and the use of new teaching methods requires extra effort for the lecturers. It is due to the fact that they must cope with the adaptation to new techniques and the consequent tuning, keeping a balance between the development of specific and generic competencies. The lecturers must be taking into account that the learning target, with a focus on the subject, appears to be the learning process. Students learn to learn, through experience and reflection on it, they learn to have a critical attitude and to develop the ability to live every context and every event as a learning resource [7].

Some different learning methodologies have been analyzed in a wide range of study cases [8-16], with the aim of improving the learning process. However, not all techniques are useful when the number of students is high [17]. This paper analyzes the use of different learning techniques in advanced engineering courses. Cooperative learning and e-learning have been applied in a fifth-year engineering course at the University of Vigo (Spain). This work also presents the students' opinion about the techniques used. Cooperative learning allows students to work in groups, which is a key point for future engineers. Moreover, this technique allows students to teach new content to each other while instructors guide them. On the other hand, teaching and learning can be facilitated by multimedia resources because they can provide motivation in the learning process. The authors expect that this work can serve as a guide for future experiences in similar cases.

\section{METHOD DESCRIPTION}

This section describes the learning methods that were object of study (Fig. 1).

The subject "Complementary Fuels" belongs to the second semester of the last year of the degree "Mining Engineer”. It is a mandatory subject that presents to the students the different alternative energies obtained from 


\section{PAPER}

\section{B-LEARNING TOOLS IN ENGINEERING EDUCATION}

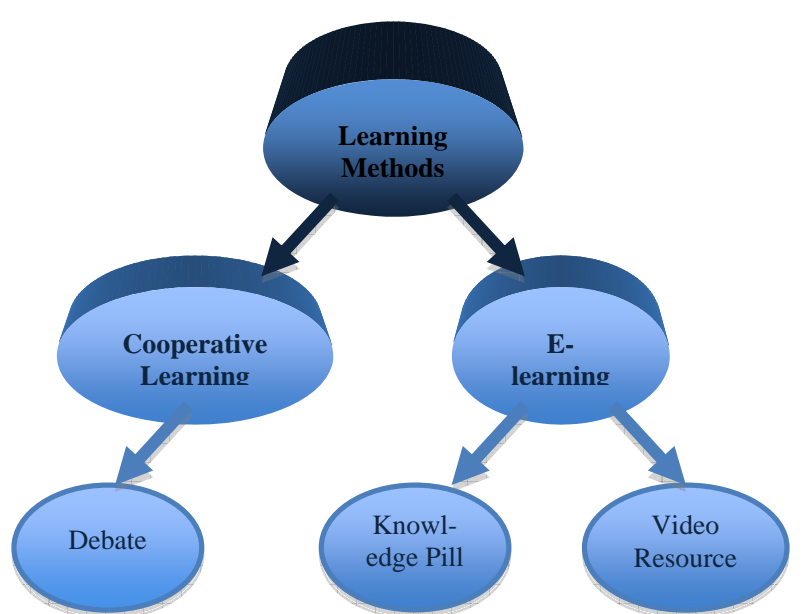

Figure 1. Scheme of learning methods used.

all types of resources, and also the energy sources of hydrogen. The course syllabus is grouped into seven main chapters: Energy outlook; Alternative Fuels; Waste as energy source; Biomass; Biofuels; Hydrogen; Fuel cells.

The course syllabus includes the definition of competencies to be developed, namely:

- Ability to design and manage of applied experimental procedures, especially the determination of thermodynamic and transport properties, and modeling of phenomena and systems in the field of chemical engineering, systems with fluid flow, heat transfer, mass transfer operations, kinetics of chemical reactions and reactors.

- Ability to interrelate all the knowledge acquired, interpreting them as components of a body of knowledge with a clear structure and strong consistency internally.

- Encourage cooperative work, communication skills, organization, planning and acceptance of responsibilities working in a multilingual and multidisciplinary education that promotes equality, peace and respect for fundamental rights.

Considering that the topics of greater impact are renewable energies and hydrogen, the authors decided to implant some learning methods, mainly based on Hydrogen Technology and Energy outlook. Moreover, the use of learning methods allows to teach the specific knowledge of each subject, and also the development of generic or transversal skills. Organization and planning, oral and written communication, foreign language learning, cooperative work, critical thinking, students' adaptation to a new situation, creativity and leadership, are skills very important in the global education of students. In most of the subjects, lectures focus on the specific skills, the main objective being the transmission of the topics included in the course syllabus.

The learning activities used in this research were accomplished during a complete semester in a class of 30 students and were carried out in sessions of one hour. Three activities of two new learning methods (cooperative learning and e-learning) were used in this research. Both methods have been used by other authors with the aim to motivate the student participation on their learning process $[18,19]$. Among all activities, authors have chosen three activities with very different objectives: the debate for a class presentation, the knowledge pill to introduce basic concepts, and the video resource to reinforce the lecture.

Knowledge pill is a tool that gives student knowledge without having to attend lessons. These pills are generally designed to guide students through information or to help students perform the specific tasks. In the knowledge pill, the screen is divided in two sections: one shows a computer desktop image and the other is the video image of the lecturer (Fig. 2). The end product is a video with good resolution including the lecturer, his/her voice and the PC background used for the presentation [20]. The aims of these pills are convenience and flexibility to learners: the learning sessions are available twenty-four hours a day (24x7). Learners are not bound to a specific day/time to physically attend lessons. In this research, the knowledge pill was used with the aim of introducing some basic concepts about hydrogen technology before the lecture. For that reason, students saw the knowledge pill at the beginning of the class before the teacher explanation. It lasted 10 minutes and after the content included in the knowledge pill was expanded to study in depth the topic and students had the possibility to clarify their doubts.

Debate refers to the process of considering different points of view and arriving at a judgement. In this case, the debate was used between two groups with the aim that on a group should convince the other to agree with them. One group has to defend the renewable energies and the other group the non renewable energies. Debate cultivates the active engagement of students, placing the responsibility of comprehension on the shoulders of the students [21]. The debate was used instead of a lecture and was carried out as follow: students were divided into two groups, and each group worked together to formulate arguments for their assigned viewpoint. Each group presented arguments in support of their position during 10 minutes. After each side had presented their arguments, the groups were given an opportunity to rebut the arguments and, time permitting, the presenters asked to respond to the rebuttal. This format was particularly useful in order to develop argumentation skills (in addition to teaching content). Each debate took approximately 40 minutes. The debate was followed by a review session when the teacher provided them with the feedback during the last 10 minutes of the class.

The video (Fig. 3) was chosen to reinforce the lecture explanation. For that reason, a documentary was used at the end of the lesson with the aim of seeing different aspects related to the introduction of hydrogen technol ogy in a real context (hydrogen vehicles, hydrogen supply

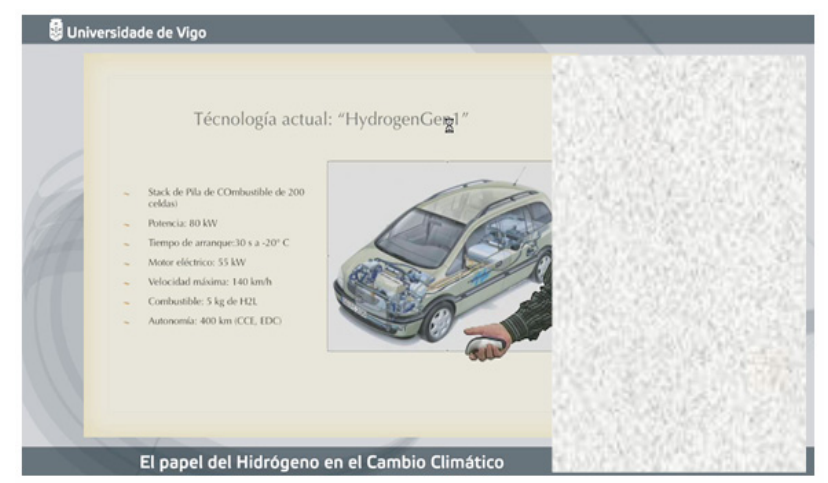

Figure 2. Snapshot of the knowledge pill used. 


\section{B-LEARNING TOOLS IN ENGINEERING EDUCATION}

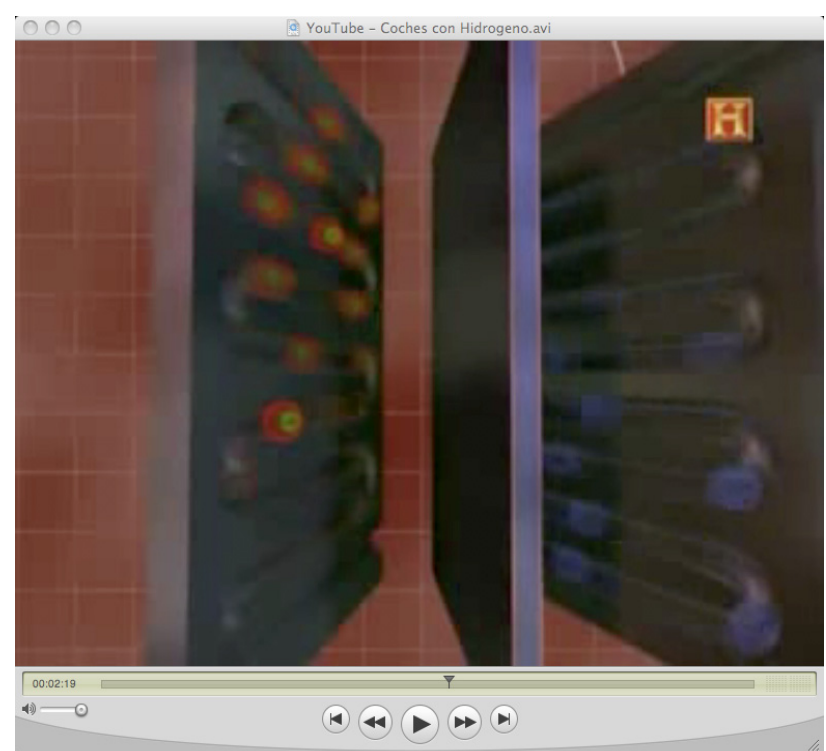

Figure 3. Snapshot of the video used.

and dispensing technology, etc.). It lasted 15 minutes and after it was discussed with the students in order to answer their doubts.

When the students finished the three activities, they answered a questionnaire to compare the three activities from the students' point of view (Fig. 4). Furthermore, considering that the knowledge pill was unknown among the students, teachers decided to include questions based on the students' opinion only about that activity. The questionnaire consists of four questions, one multiplechoice question and three open ended questions. In the first open ended question, the students had to indicate the most useful technique from a didactic point of view and their reasons. The other questions were based on the knowledge pill due to the novelty of this technique among the students. For that reason, in the multiplechoice question the students were asked if they considered that this technique is useful to improve the learning process. The possible answers were: (a) a lot, (b) quite a lot, (c) little and (d) nothing. Finally, in the other two questions they were asked to mention two positive and two negative aspects of the knowledge pill.

The assessment of the course is distributed like that: $20 \%$ final theory exam, $40 \%$ attendance to theoretical classes and participation in the activities, 40\% final work. The three activities were not evaluated individually. However, at the end of the course the students had to do an exam covering all the topics of the course. The exam included questions about topics which had been taught with traditional lectures and questions about topics which had been taught with the new methods. This allows to check if the knowledge had been acquired in all cases.

\section{RESULTS AND DISCUSSION}

This section gives an analysis of the results of the application of the different learning methods. The evaluation of the different techniques is based on students' opinion. The principal purpose of evaluating different learning technologies is to provide an idea regarding the effectiveness of the innovation in an engineering course.

The first aim was to know the students' preferences regarding the three activities. For that reason, the first ques- tion was based on knowing which was the best activity to improve the learning process and motive the student. The results (Fig. 5) show that the majority of the students preferred the video and the rest of students chose the debate. Moreover, two main ideas appeared in the students' answers: the video has the advantage of synthesizing the topic and shows examples of real life while the debate opens the opportunity for the development of empathy. One student, who had chosen the video, said: "it seems interesting to see something that supports what the teacher explains". Another student explained: "a debate allows to discuss different points of view". Thus, the main objective of the authors had been achieved; since the idea of using a video was based on summarizing the lecture and introducing the students in the real world; whereas, the debate was used to analyze different points of view of the same topic. On the other hand, debate develops critical thinking skills, oral communication skills, and empathy. Participation in a debate requires a more thorough mastery of the content than even giving a lecture does [22].

The results obtained from the questionnaire about knowledge pill were better than the authors expected because the answers covered all the teachers' objectives. Although students had preferred the other two activities, $100 \%$ of students chose the option (b). Then, it is also a good activity in order to improve the students' learning

1. Comparing the three activities, indicate the most useful to improve the learning process and why.

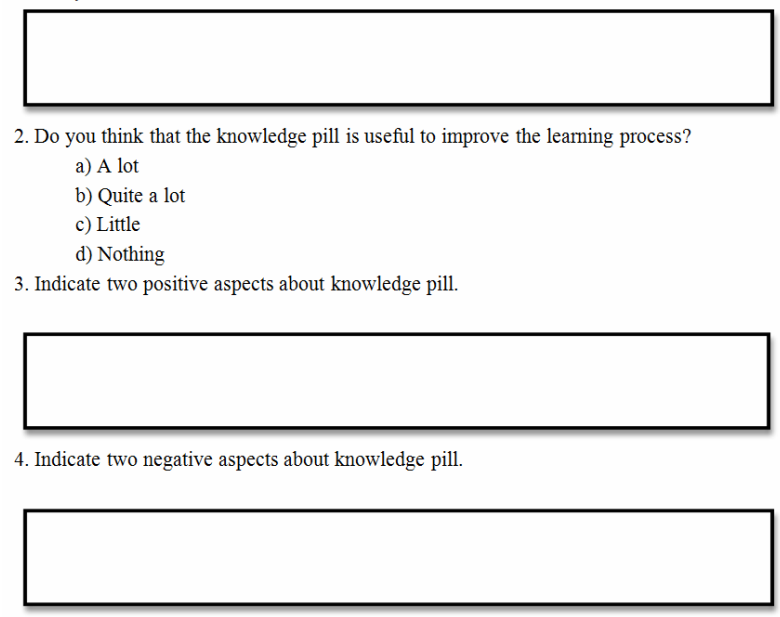

Figure 4. Questionnaire.

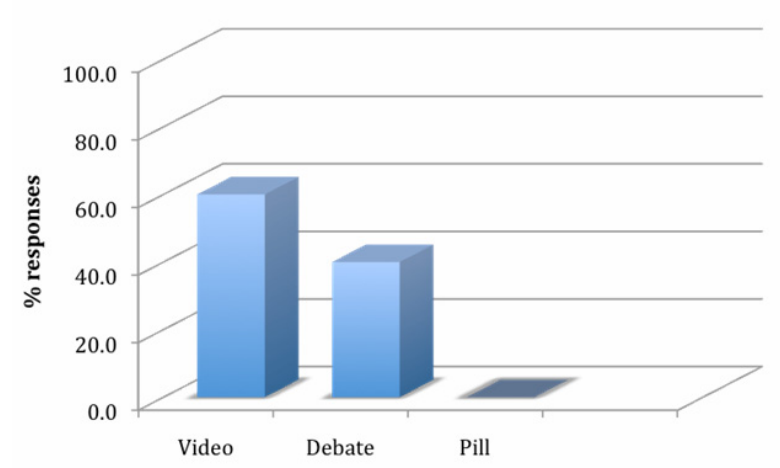

Figure 5. Preferences of students about the used learning methods.

process. The answers expressed their enjoyment and satisfaction and pointed out the novelty of the activity: "more pleasant classes", “it's an innovative technique”, 


\section{B-LEARNING TOOLS IN ENGINEERING EDUCATION}

"you can reuse it if you need it". However, one student was doubtful and uncertain about the technique because the technique does not allow students to ask questions during the teacher's explanation. However, taking into account that the knowledge pill was used during a lecture, this negative point was solved since the students could solve their doubts after watching the knowledge pill.

In the present work, the questionnaire was made to compare only the three activities. However, in the open questions the students tend to include comparison with the traditional lectures. The answers indicated that they felt these methods were better than the traditional way of teaching. Almost all students expressed their enjoyment and satisfaction after experiencing a new learning environment. Most students said that the idea of using innovative techniques in the class had been stimulating, fun and enriching. Therefore, the students benefit when professor used new learning methods to promote the active engagement.

Finally, the final exam consist of eight multiple-choice questions: three about topics that had been taught with new learning methods and five about the topics taught in the lectures. All the questions presented the same difficulty. All the students passed the exam; however, it was observed that the students answered better the questions that included concepts about the topics that had been taught with new learning methods, since the $96.3 \%$ of the students answered correctly the questions related to Hydrogen and Energy outlook. This finding agrees with the results obtained by other authors [9].

The results of the exam are shown in Fig. 6. This figure shows the number of right answers per students and among the right questions which were related to new methods or the traditional methods. It can be seen that the most of the students answered well the three questions related to learning methods. For that reason, it can be concluded that involving students in the learning process assists them in gaining a better understanding of the course material and allows them to transfer their classroom knowledge to practical applications.

Taking into account the exam results and the students' opinion reflected on the questionnaire, it can be said that the utilization of different learning techniques has had the following benefits:

1. Promote student learning and academic achievement;

2. Increase student retention;

3. Enhance student satisfaction with their learning experience;

4. Help students develop skills in oral communications;

5. Develop students' social skills;

6. Promote student self-esteem and help to promote positive race relations.

The benefits 1 and 2 have been proved with the obtained marks in the final exam; while the other benefits are reflected on students' opinion (3) and also in the development of the debate since this activity help students in transversal skills (4-6) The benefits of using different learning methods as an instructional strategy also include that the students' approach dramatically changes from a

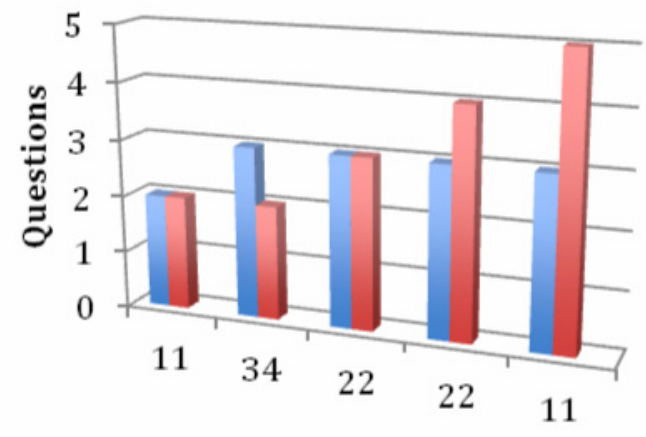

Students \%

Figure 6. Exam results: questions related to learning methods (blue), other questions (red).

passive approach to an active one [21] and "students place a higher value on learning by participating than on learning by being lectured at and receiving information passively" [23].

However, it presents the serious drawback of requiring a considerable initial workload for instructors to begin. Nevertheless, without any doubt, restructuring the subject has been a worthy experience that has allowed keeping the attention and the interest of most of the student.

\section{CONCLUSIONS}

In this paper is some combination of technology and traditional classroom instruction (called Blended Learning) has been used to improve students' learning process. Students learn more effectively by actively analyzing, discussing, and applying content in meaningful ways rather than by passively absorbing information. Learning activities foster student motivation and improve their retention, assimilation, understanding, and proper application of course content. The results of this study show a good acceptance of learning activities among the students. For that reason, authors recommend to lecturers take the initiative to learn and try other teaching methods and to mix and match them to maximise learning among students. For the next year, authors will keep on working in searching of other techniques to improve the students' learning process and the design of new activities to motivate the daily work of the students. Moreover, it is necessary some improvements must be carried out to obtain a better evidence of the obtained data.

\section{REFERENCES}

[1] A.N. Whitehead, The Aims of Education and Other Essays, Ed. Macmillan, 1929.

[2] M. Birenbaum, Assessment preferences and their relationship to learning strategies and orientations. Higher Educ., vol. 33, pp. 7184, 1997. http://dx.doi.org/10.1023/A:1002985613176

[3] G. Wiggins, Educative Assessment, Designing Assessments to inform and Improve Student performance, The Jossey-Bass Education Series, 1998.

[4] R.J. Beck, N.L. Livne, and S.L. Bear, Teachers' self-assessment of the effects of formative and summative electronic portfolios on professional development. Eur. J. Teach. Educ., vol. 28, pp. 221244, 2005. http://dx.doi.org/10.1080/02619760500268733

[5] G. Pinto, The Bologna Process and Its Impact on University-Level Chemical Education in Europe. J. Chem. Educ., vol. 87, pp. 11761182, 2010. http://dx.doi.org/10.1021/ed1004257 


\section{PAPER \\ B-LEARNING TOOLS IN ENGINEERING EDUCATION}

[6] B.L. McCombs, and J.S. Whisler, The learner-centered classroom and school. San Francisco: Jossey-Bass Publishers, 1997.

[7] J. Mezirow, Cognitive Processes Contemporary Paradigms of Learning, in Sutherland P., Adult Learning: A Reader. Sterling VA, Kogan, 1998.

[8] P. Ambrogi, M. Caselli, M. Montalti, and M. Venturi, Make sense of nanochemistry and nanotechnology, Chem. Educ. Res. Pract., vol. 9, pp. 5-10, 2008. http://dx.doi.org/10.1039/b801285g

[9] C.M. Davis-McGibony, Protein-Sequencing Jigsaw. J. Chem. Educ., vol. 87, pp. 409-411, 2010. http://dx.doi.org/10.1021/ed800 $\underline{1144}$

[10] N. Natho, L. Knipping, O. Pfeiffer, C. Schröder, E. Zorn, and S. Jeschke. Collaborative learning in teaching information management. Eur. J. Eng. Educ., vol. 35, pp. 405-413, 2010. http://dx.doi.org/10.1080/03043797.2010.483278

[11] A.M. Norintan, Learning through teaching and sharing in the jigsaw classroom. Ann. Dentistry, vol. 15, pp. 71-76, 2008.

[12] P.T. Terenzini, A.F. Cabrera, C.L. Colbeck, J.M. Parente, and S.A. Bjorkland, Collaborative learning vs. lecture/discussion: Students' reported learning gains. J. Eng. Educ., vol. 90, pp. 123-130, 2001. http://dx.doi.org/10.1002/j.2168-9830.2001.tb00579.x

[13] S.E. Walker, Active learning strategies to promote critical thinking. J. Athletic Trainers, vol. 38, pp. 263-270, 2003.

[14] T. Wolfskill, and D. Hanson, A New Model for Computer Assisted Learning. J. Chem. Educ., vol. 78, pp. 1417-1424, 2001. http://dx.doi.org/10.1021/ed078p1417

[15] G. Stahl, Group cognition: Computer support for building collaborative knowledge. Cambridge, MA: MIT Press. 2006, Retrieved fromhttp://www.cis.drexel.edu/faculty/gerry/mit/.

[16] G.E. Marsh, A.C. McFadden, Price, B.J. Blended Instruction: Adapting Conventional Instruction for Large Classes. Online J. Distance Learning Administration 2003, Retieved from http://www.westga.edu/ distance/ojdla/winter64/marsh64.htm

[17] R. Maceiras, M.A. Cancela, A. Sánchez, and S. Urréjola. Experience of cooperative learning in engineering. Eur. J. Eng. Educ., vol. 36, pp. 13-19, 2011. http://dx.doi.org/10.1080/03043797. $\underline{2010.518232}$

[18] D.W. Johnson, R.T. Johnson, and M.E. Stanne, Cooperative learning methods: A meta analysis. Minneapolis, MN: University of Minnesota Press, 2000.
[19] R. Kennedy, In-Class Debates: Fertile Ground for Active Learning and the Cultivation of Critical Thinking and Oral Communication Skills. Int. J. Teach. Learn. Higher Educ., vol. 19, pp. 183-190, 2007.

[20] R. Maceiras, A. Cancela, and V. Goyanes, Aplicación de Nuevas Tecnologías en la Docencia Universitaria, Formación Universitaria, vol. 3, pp. 21-26, 2009.

[21] A. Snider, and M. Schnurer, Many sides: Debate across the curriculum. New York: International Debate Education Association, 2002.

[22] L. Lewin, and J. Wakefield, Teaching psychology through an instructor-debate format. Teach. Psychol., vol. 10, pp. 115-116, 1983. http://dx.doi.org/10.1207/s15328023top1002_20

[23] R. Berdine, Increasing student involvement in the learning process through debate on controversial topics. J. Marketing Educ., vol. 9, pp. 6-8, 1987. http://dx.doi.org/10.1177/027347538700900303

\section{AUTHORS}

R. Maceiras is professor of the Defense University Center at the Naval Academy, attached to the University of Vigo. In Marín, Spain. Ph.D. on Chemical Engineering. (e-mail: rmaceiras@uvigo.es).

A. Cancela is professor of the Chemical Engineering Department at the University of Vigo, Ph.D. on Chemical Engineering (e-mail: chiqui@uvigo.es).

A. Sánchez is professor of the Chemical Engineering Department at the University of Vigo, Ph.D. on Chemical Engineering (e-mail: asanchez@uvigo.es).

R. Maceiras is professor of the Defense University Center at the Naval Academy, attached to the University of Vigo. In Marín, Spain. Ph.D. on Chemical Engineering (e-mail: rmaceiras@uvigo.es).

Received 17 December 2012. Published as resubmitted by the authors 18 March 2013. 